\title{
REVIEW
}

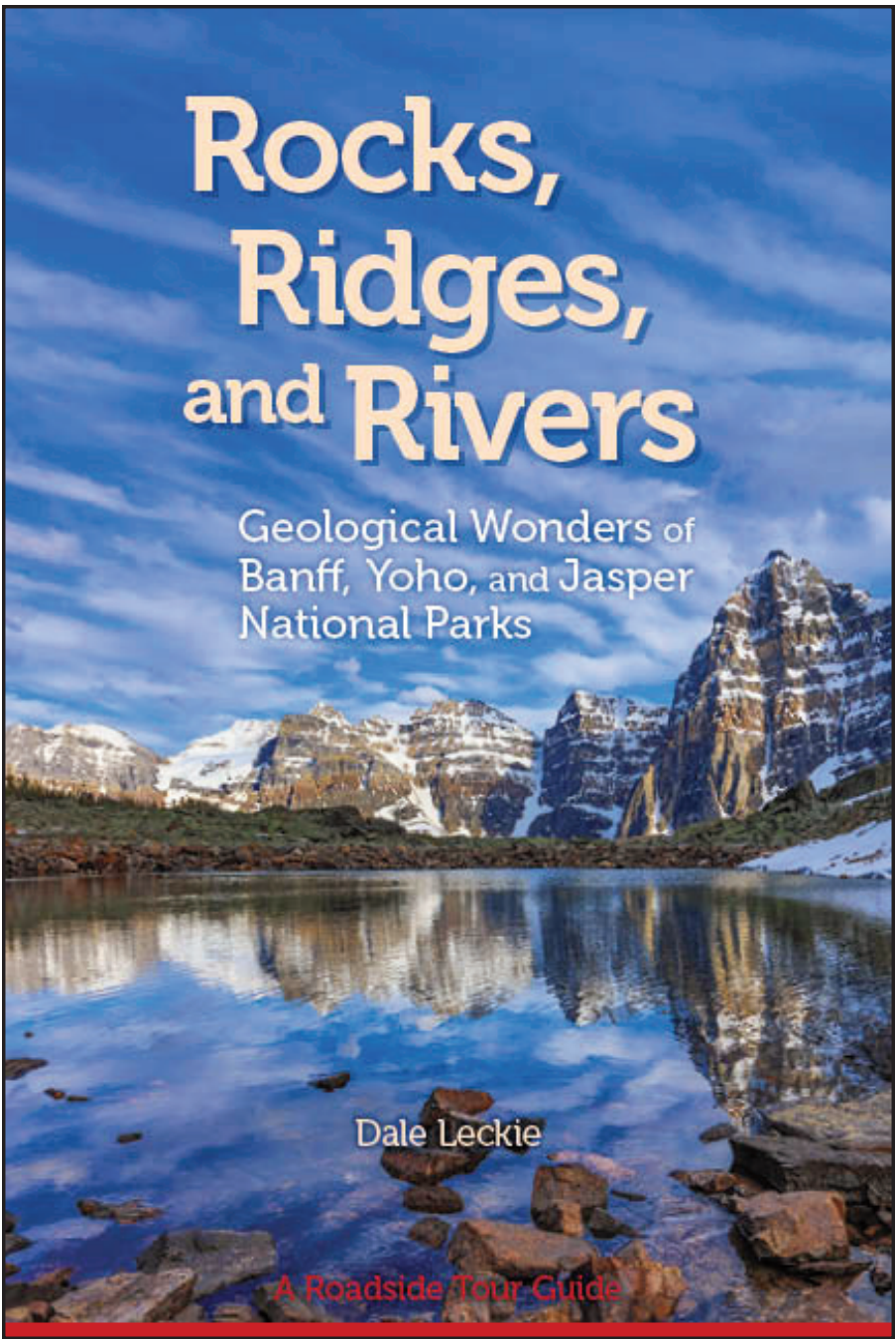

\section{ROCKS, RIDGES, AND RIVERS: Geological Wonders of Banff, Yoho, and Jasper National Parks. A Roadside Tour Guide}

\section{Dale Leckie}

Published by: Broken Poplars Press; distributed by Sandhill Book Marketing and Alpine Book Peddlers. Also available from Chapters Indigo in Canada.
Published: 2017; 216 p.

Purchase price: \$27.95 (CND); Electronic version available E-mail:leckied@shaw.ca

\section{Reviewed by Andrew Kerr}

Memorial University

Department of Earth Sciences

St. John's, Nenfoundland and Labrador, A1B 3X5, Canada

E-mail:akern@mun.ca

Dale Leckie is an ex-Geological Survey of Canada geologist, a former Chief Geologist for Wascana Energy (later Nexen) and now an adjunct professor at the University of Calgary. Dale has a long-standing interest in the majestic Rocky Mountains and their formation over several hundred million years, and he is known as an expert on the Cretaceous rocks of western Canada. In 2016, he was awarded the R.J.W. Douglas Medal by the Canadian Society of Petroleum Geologists for his contributions to sedimentology and regional geology. After authoring or coauthoring numerous technical publications over many years, he has now turned his hand to writing a general guidebook about his favourite field areas, which I have thoroughly enjoyed reading at intervals over the last three months. Many of us contemplate writing such books, but few of us can accomplish the task, which is easy to conceive but very difficult to fulfill. I know this only too well, because I have had a rather similar project on my own very crowded back burner for many years. As far as I know, this is Dale's first effort in the direction of Geoscience Outreach, but I certainly hope it will not be his last such excursion. In this compact yet highly informative book, he has managed to successfully balance the divergent needs of professionals, informed amateurs and those who lack a geoscience background, and has provided us with an excellent model for a regional guidebook at an intermediate level. I have certainly drawn much from it in the way of presentation ideas, and with luck it might assist me to actually get something done with that lingering back burner project.

The challenges in developing such a project are well known to many of us. As geoscientists, we need to convey stories that involve hundreds of millions of years, thousands of kilometres of motion, or more likely both of these and much more, to explain a world that appears superficially unchanging. The concepts of deep time and great distance, and the need to think in three dimensions and often in four, seem familiar to us, although I still question whether any of us truly comprehend the immensity of geological time. But for those who 
encounter such ideas for perhaps the first time, making links between such ideas and what is observed in nature is a leap that often defeats understanding. On top of this, like all sciences, geology has its own language, which is sometimes impenetrable to geologists themselves, let alone nonspecialists. To visualize geology in any given place will always require some stratigraphic nomenclature and the basics of the geological time scale. The language of geoscience is itself sometimes a moving target on a time scale measured in decades rather than by millennia.

To accommodate such diversity of readership, a good geoscience guidebook needs a glossary and some clear explanation of concepts. Rocks, Ridges, and Rivers adopts the approach of many such efforts by placing the glossary towards the end of the book, on the reasonable assumption that not all readers will need to consult it. As I read through the text and admired its illustrations, I purposely checked for definitions and explanations of familiar technical terms, and was happy to find that almost all were accessible in the glossary and well explained in simple language with cross-references. The subdivision of the glossary into an initial section for technical terms and then a second index to the principal stratigraphic units is also a good idea, which will certainly help the reader - even experienced geologists are likely to need the latter. There is a 'quick reference chart' for the stratigraphy that also illustrates lateral facies transitions and the idea of time-equivalence between some of the formations. The placement of this chart on the inside front cover, with a complementary summary of the geological time scale on the inside back cover, is ideal for easy reference. There is no doubt that understanding a book about geology can present challenges for a nonspecialist (and sometimes for other geologists!) but my judgement is that the approach used here serves well for a wide range of readers.

The organizational structure of the book clearly was given much thought by the author, and it also helps those without specialist knowledge. The first chapter gives some necessary logistical information and obligatory safety advice, and then moves to a concise but clearly written account of the regional geology and tectonics of the Canadian Rockies. I am no expert on Cordilleran geology and I found Dale's treatment to be comprehensive and informative, without any information overload.' I am sure that his review involves some skilful simplification of contrasting opinions, but this is exactly what is needed in this context, and the book's references are there for those who need more. This skilful first chapter places the individual excursions that follow within a wider context, and also previews them in many respects, but avoids burying the reader in a landslide of formation names. There is also an excellent 'trip planner' chart which gives vital information about the stops within each excursion, which trips are associated with essential or optional hiking excursions, and the distances and other constraints involved. Readers interested in gently stretching their legs with short strolls or acquiring blisters on longer treks will quickly know which of the subsequent sections best meets their needs. The chart is linked conveniently to a summary map of the excursions on preceding pages, with a con-

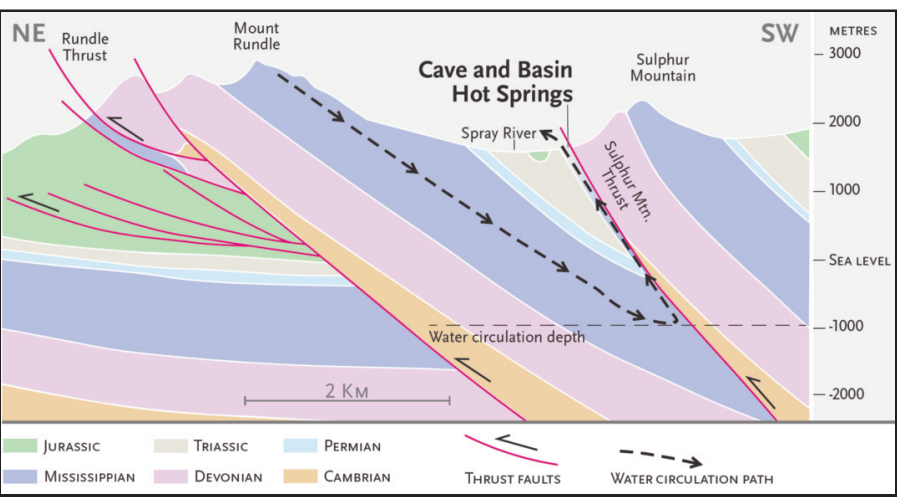

Schematic cross-section showing the area around the Banff Hot Springs and illustrating the processes involved in their generation (from Leckie 2017, p. 71; after Grasby et al. 2003 and Price 1970).

sistent colour coding to easily locate the areas of greatest interest or proximity.

There are eight Geological Experiences in the main body of this guide, which cover a route from Calgary to the area around Jasper, including parts of the three main National Parks of the Canadian Rockies - Banff, Yoho, and Jasper. I have not added up the total distances involved along the Trans-Canada Highway and several other highways in Alberta and British Columbia, but to complete the entire route would certainly involve several days and several hundred kilometres. The route begins in the Banff area, goes westward past Lake Louise, and then over the continental divide to the area around Field in British Columbia, home of Yoho National Park and the famous Burgess Shale. From there, it proceeds northwest along the spine of the Rockies, following the Icefields Parkway to Jasper, and closes with sections covering the area of Jasper townsite, the Maligne River area, and part of Jasper National Park. These individual experiences include between four and eleven specific geological localities, which vary widely in their nature. Roadside outcrops are in a minority for obvious safety reasons, and many such stops are viewpoints, for equally obvious reasons - this is an area where large-scale geology can best be appreciated from a distance. The mountain vistas are helpfully illustrated with annotated photos and diagrams. Indeed, as discussed below, the wealth of illustrative material is a major strength of this book. The longest and most complex section of the book is the one concerned with the Icefields Parkway region. Some stops involve hikes, either to access the sites or viewpoints, or to illustrate features on a larger scale than individual outcrops can ever do. The hikes are also scenic excursions that will provide outdoor experiences that go well beyond geology. Readers with knowledge will probably expect that stratigraphy and structure - notably thrust tectonics would form the technical core of any book about the Canadian Rockies, but this is not entirely the case. Many stops also incorporate information on geomorphology and glacial landforms, and some have a distinct historical aspect, as in the case of Banff Hot Springs. Some attention is also paid to examples of early mining, and to the wider relevance of geology to petroleum resources. I applaud the effort to convey the economic importance of geoscience, even if it isn't a primary goal for such a book. 
Two aspects of the Geological Experiences merit special mention. The first is a sensible hierarchy of stop locations - each core excursion is a progression of sites along or very close to the highway corridors, for which access hikes are easy and brief. But alongside this core are optional side trips, labelled 'nearby and interesting,' which provide diversions for those who seek longer hikes, or have a specific interest in a given topic. This arrangement is ideal for planning a mixture of activities, especially in conjunction with the summary table and maps in the first part of the book. The second feature that I admired was the inclusion of specific sections containing more detailed scientific information on topics of particular interest. These are built into the more general descriptions of excursions, but they amplify concepts and information introduced in the first part of the book. I found the treatment of the legendary Burgess Shale fauna and their scientific importance to be very useful and informative. These are not really 'sidebars' in the conventional sense of the word, as they are not separated from the main text, but they play the same role in conveying details that will be important to those with a geoscience background. Other sections of this nature elaborate on topics ranging from the intense colours of mountain lakes to an explanation of hot springs in the Banff area.

Geoscience really is a visual topic, and good graphics and thoughtful graphic design are to me the essence of any book that emphasizes field geology. Conversely, poor graphics are the downfall of many a paper, as those of us in the editorial world know only too well. Rocks, Ridges, and Rivers truly excels in the area of graphical illustration, and I think it provides a good model for this aspect of guidebooks. The maps and illustrative sections are all coloured, and they are clear in construction and easily legible without excessive detail. Their format is consistent and their captions are informative. The temptation to simply reuse existing material designed for more specialized purposes without proper simplification was avoided. In fact, the book had a dedicated designer, Sergio Gaytán, who richly deserves the short biographical note at the close of the book. Authors of scientific papers - or at least some of them - could really benefit from looking at some of the figures and other material in this book as examples. To help encourage this, a few examples are included as part of this review, with the kind permission of Dale and his publishers.

The book contains many excellent photographs, most of which come from the author. Given that many stops are mountain vistas, these are not only eye-catching, but very important to convey interpretations and context. Another notable feature of the book is its use of creative artwork in the form of many paintings that showcase the work of Heather Pant. Her colourful and at times slightly other-worldly landscapes augment the traditional photos, and are to be admired in their own right. There are many shared possibilities between geologists and artists, as both produce interpretative works that may not be true in scale or realistic in depiction, but which emphasize important things and leave a lasting impression. For the appreciation of readers and to recognize her great talent, one of Heather's images is also included as part of this review.

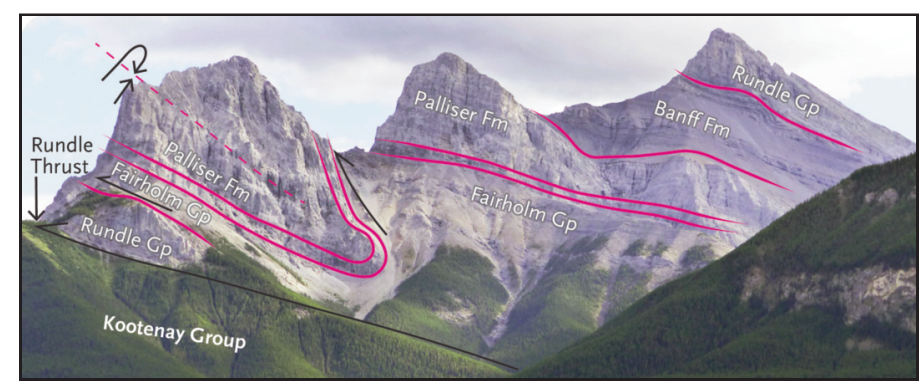

The Three Sisters, part of the South Banff Range, Canadian Rockies, annotated to show a typical combination of stratigraphy and structure (from Leckie 2017, p. 51).

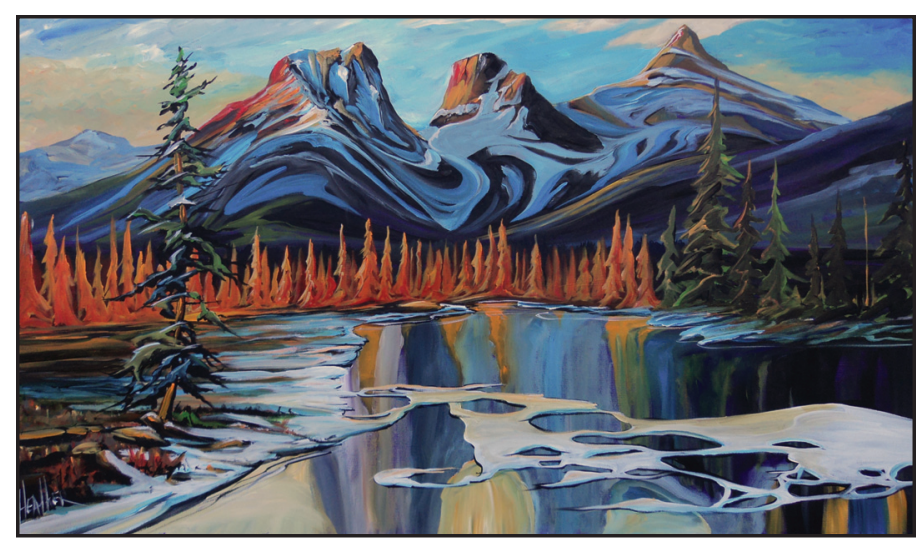

"Three Sisters Resplendence", acrylic on canvas, 15 by 30 inches. Painted by Heather Pant and reproduced with her kind permission (from Leckie 2017, p. 39). For more examples of the artist's work, visit www. heatherpant.com.

Overall, Rocks, Ridges, and Rivers is a first-class guidebook that is skilfully designed for a diverse audience, which showcases up-to-date scientific data in an attractive and readable manner. The illustrations alone provide much enjoyment and also clear and useful information that complements the well-written text. This is a first-class effort of which the author and publishers should be proud, and I sincerely hope that Dale and his collaborators might soon apply their skills to other areas of Canada.

\section{REFERENCES}

Grasby, S.E., van Everdingen, R.O., Bednarski, J., and Lepitzki, D.A.W., 2003, Travertine mounds of the Cave and Basin National Historic Site, Banff National Park: Canadian Journal of Earth Sciences, v. 40, p. 1501-1513, https://doi.org/10.1139/e03-058.

Price, R.A., 1970, Geology, Canmore (west half), west of Fifth Meridian, Alberta: Geological Survey of Canada, "A" Series Map 1266A, scale: 1:50,000, https://doi.org/10.4095/108954. 


\section{GEOLOGICAL ASSOCIATION OF CANADA (2017-2018)}

\section{Corporate Members}

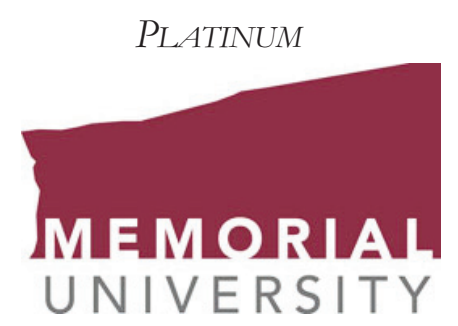

GOLD

\section{(Q) AngloAmerican}

Anglo American Exploration (Canada) Ltd.

Northwest Territories Geological Survey

ROYAL TYRRELL
MUSEUM

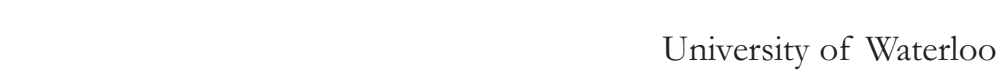

GEOSCIENCE CANADA AND THE GEOLOGICAL ASSOCLATION OF CANADA ARE GRATEFUL TO THE CANADIAN GEOLOGICAL FOUNDATION FOR THEIR FINANCLAL SUPPORT OF THIS JOURNAL.

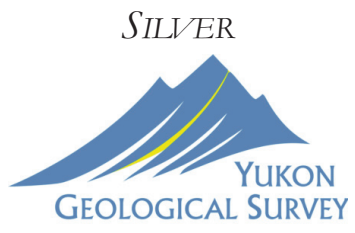

NICKEL
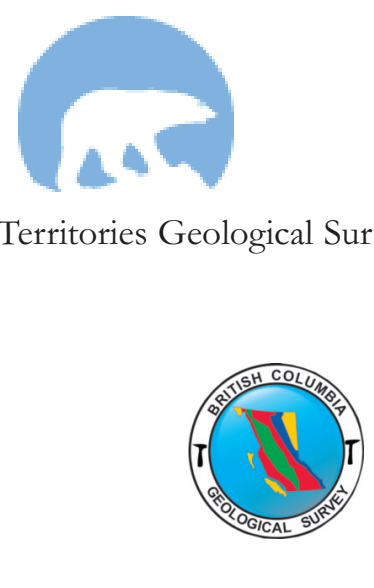